\title{
Article \\ Gender and Socioeconomic Inequality in the Prescription of Direct Oral Anticoagulants in Patients with Non-Valvular Atrial Fibrillation in Primary Care in Catalonia (Fantas-TIC Study)
}

\author{
$M^{a}$ Rosa Dalmau Llorca ${ }^{1,2,3,+} \ddagger\left(\mathbb{D}\right.$, Carina Aguilar Martín 3,4,5,,$+ \ddagger$, Noèlia Carrasco-Querol ${ }^{3,4,6, *(\mathbb{D})}$, \\ Zojaina Hernández Rojas 1,2,3, Emma Forcadell Drago 1,3, Dolores Rodríguez Cumplido ${ }^{3,7}$ (D), \\ Elisabet Castro Blanco ${ }^{2,3}$, Josep $M^{\text {a }}$ Pepió Vilaubí ${ }^{3}$, Alessandra Queiroga Gonçalves ${ }^{3,4,8, *, \ddagger(D)}$ \\ and José Fernández-Sáez $2,3,4,6$,
}

\section{check for}

updates

Citation: Dalmau Llorca, M.R. Aguilar Martín, C.; Carrasco-Querol, N.; Hernández Rojas, Z.; Forcadell Drago, E.; Rodríguez Cumplido, D.; Castro Blanco, E.; Pepió Vilaubí, J.M.; Gonçalves, A.Q.; Fernández-Sáez, J. Gender and Socioeconomic Inequality in the Prescription of Direct Oral Anticoagulants in Patients with Non-Valvular Atrial Fibrillation in Primary Care in Catalonia (Fantas-TIC Study). Int. J. Environ. Res. Public Health 2021, 18, 10993. https://doi.org/10.3390/ ijerph182010993

Academic Editor: Paul B. Tchounwou

Received: 22 September 2021

Accepted: 16 October 2021

Published: 19 October 2021

Publisher's Note: MDPI stays neutra with regard to jurisdictional claims in published maps and institutional affiliations.

Copyright: (c) 2021 by the authors. Licensee MDPI, Basel, Switzerland. This article is an open access article distributed under the terms and conditions of the Creative Commons Attribution (CC BY) license (https:// creativecommons.org/licenses/by/ $4.0 /)$.
1 Equip d'Atenció Primària Terres de l’Ebre, Institut Català de la Salut, 43500 Tortosa, Catalonia, Spain; rdalmau.ebre.ics@gencat.cat (M.R.D.L.); zojahernandez@gmail.com (Z.H.R.); eforcadellg.ebre.ics@gencat.cat (E.F.D.)

2 Campus Terres de l'Ebre, Universitat Rovira i Virgili, 43500 Tortosa, Catalonia, Spain; elicasblan@gmail.com (E.C.B.); jfernandez@idiapjgol.info (J.F.-S.)

3 Primary Care Intervention Evaluation Research Group (GAVINA Research Group), IDIAPJGol Terres de 1'Ebre, 43500 Tortosa, Catalonia, Spain; caguilar.ebre.ics@gencat.cat (C.A.M.); drficf@gmail.com (D.R.C.); josepmp54@gmail.com (J.M.P.V.)

4 Terres de l'Ebre Research Support Unit, Foundation University Institute for Primary Health Care Research Jordi Gol i Gurina (IDIAPJGol), 43500 Tortosa, Catalonia, Spain

5 Unitat d'Avaluació, Direcció d'Atenció Primària Terres de l'Ebre, Institut Català de la Salut, 43500 Tortosa, Catalonia, Spain

6 Unitat de Recerca, Gerència Territorial Terres de 1'Ebre, Institut Català de la Salut, 43500 Tortosa, Catalonia, Spain

7 Hospital Universitari de Bellvitge, Institut Català de la Salut, 08907 Barcelona, Catalonia, Spain

8 Unitat Docent de Medicina de Familia i Comunitària, Tortosa-Terres de l'Ebre, Institut Català de la Salut, 43500 Tortosa, Catalonia, Spain

* Correspondence: ncarrasco.querol@gmail.com (N.C.-Q.); aqueiroga@idiapjgol.info (A.Q.G.)

+ Co-first author, these authors, M. Rosa Dalmau Llorca and Carina Aguilar Martín, contributed equally to this work.

$\ddagger$ Co-senior authors: M. Rosa Dalmau Llorca, Carina Aguilar Martín, Alessandra Queiroga Gonçalves and José Fernández-Sáez. M. Rosa Dalmau Llorca is the Principal Investigator of this study.

Abstract: Background: Evidence points to unequal access to direct oral anticoagulant (DOAC) therapy, to the detriment of the most socioeconomically disadvantaged patients in different geographic areas; however, few studies have focused on people with atrial fibrillation. This study aimed to assess gender-based and socioeconomic differences in the prescriptions of anticoagulants in people with non-valvular atrial fibrillation who attended Primary Care. Method: A cross-sectional study with real-world data from patients treated in Primary Care in Catalonia (Spain). Data were obtained from the SIDIAP database, covering 287 Primary Care centers in 2018. Results were presented as descriptive statistics and odds ratios estimated by multivariable logistic regression. Results: A total of 60,978 patients on anticoagulants for non-valvular atrial fibrillation were identified: 41,430 (68\%) were taking vitamin K antagonists and 19,548 (32\%), DOACs. Women had higher odds of treatment with DOAC (adjusted odds ratio [ORadj] 1.12), while lower DOAC prescription rates affected patients from Primary Care centers located in high-deprivation urban centers (ORadj 0.58) and rural areas (ORadj 0.34). Conclusions: DOAC prescription patterns differ by population. Women are more likely to receive it than men, while people living in rural areas and deprived urban areas are less likely to receive this therapy. Following clinical management guidelines could help to minimize the inequality.

Keywords: direct oral anticoagulants; vitamin K antagonists; atrial fibrillation; socioeconomic inequalities; sex-related differences 


\section{Introduction \\ Gender-Based and Socioeconomic Differences in Health Care and Drug Prescription}

Oral anticoagulants are the drugs of choice to prevent stroke in people with atrial fibrillation. In non-valvular atrial fibrillation, two classes of oral anticoagulants are available for preventing a thromboembolic event: vitamin $\mathrm{K}$ antagonists (VKA) and direct oral anticoagulants (DOAC). VKAs are characterized by a narrow therapeutic window, require frequent follow-ups, are effective for preventing stroke, increase the risk of bleeding, can be used in people with any degree of renal insufficiency, and are less expensive than DOACs. For their part, DOACs do not require monitoring, effectively prevent stroke, and also increase the risk of bleeding, although to a lesser extent than VKAs for intracranial bleeding [1,2].

The cost and follow-up profile of a given treatment can influence its prescription differently depending on certain factors and contexts. For example, prescription patterns can be conditioned by sociodemographic and economic factors that are unrelated to medication appropriateness criteria [3].

Different authors have analyzed the influence of deprivation in health inequalities, at both a national and international level [4-7]. Deprivation has been conceptualized since the 1970s [4], differing from the classical concept of poverty in that it is linked to difficulties (capability) in access to employment, education, culture and social development at levels considered acceptable for society. The concept of deprivation thus encompasses more than food insecurity, lack of basic goods such as clothing, sub-standard housing and other purely economic or monetary indicators of well-being, in consonance with a holistic model of health [8]. In Spain, several studies have applied deprivation indexes to different settings based on the MEDEA project ("Mortality and socioeconomic and environmental inequalities in small Spanish areas") [8]. In England, socioeconomic deprivation was associated with opioid and non-opioid analgesics, antipsychotics and reflux medication prescriptions, while affluence was associated with epinephrine, combined oral contraceptives and hormone replacement therapy [9]. A recent meta-analysis showed that the rate of prescription of guideline-recommended medications in managing acute coronary syndrome was significantly different between patients with the lowest and the highest socioeconomic status [10]. Regarding oral anticoagulants, in Sweden, differences by age, income, education and country of birth were found in their prescribing after stroke. Those differences were not explained by common risk factors, indicating socioeconomic inequalities in the prescribing of preventive treatment after stroke [11]. In Denmark, patients with atrial fibrillation who had a low income, low education and were living alone were associated with a lower chance of being initiated with oral anticoagulation therapy, and new high-cost drugs were increasing inequality [12]. To date, few studies have assessed inequalities in the prescription of DOACs, which are more expensive than VKA, in patients with atrial fibrillation [6,13]. There are those that have highlighted the substantial disparities that exist around access to new anticoagulant therapies in the USA among socioeconomically disadvantaged patients and the need to study inequalities related to the prescription of oral anticoagulants [6,13]. Differences in DOAC prescription patterns have already been observed in relation to socioeconomic indicators [6]. Yet, any analysis of socioeconomic determinants must also take into account the gender dimension, as this is the relational aspect that governs how sex interacts with the world around it [14,15]. There is evidence that oral anticoagulants are prescribed less frequently to women compared to men with atrial fibrillation [16]; although, few studies have evaluated the variety of anticoagulant prescribed by gender [13]. Not enough information is currently available regarding gender-based and socioeconomic differences in DOAC prescription in our geographical area.

Studying gender-based and socioeconomic differences in health care is essential for identifying modifiable causes of inequality and developing solutions to guarantee equity and quality in health care. The aim of this study is to assess gender-based and 
socioeconomic differences in the prescription of DOACs in people with non-valvular atrial fibrillation seen in Primary Care in Catalonia (Spain).

\section{Materials and Methods}

\subsection{Study Design and Population}

As part of the Fantas-tic study in Catalonia, we used a cross-sectional design and real-world data from patients seen in Primary Care centers (PCCs) managed by the Catalan Health Institute (ICS). The 287 PCCs included employ 3384 physicians and are responsible for the care of an estimated 5,564,292 people, about $80 \%$ of the Catalan population. All registered patients diagnosed with non-valvular atrial fibrillation and treated with oral anticoagulants in 2018 were included.

Data were drawn from the SIDIAP database (Information System for Research in Primary Care), a representative population-based database in Catalonia that collects anonymized clinical information from different data sources: (a) electronic health records from ICS Primary Care, including sociodemographic characteristics, registered diagnoses coded according to the International Classification of Diseases, 10th revision (ICD-10) [17], general practitioner prescriptions and clinical parameters; (b) laboratory data; and (c) prescription data from the Catalan Health System community pharmacies, based on the Anatomical Therapeutic Chemical (ATC) Classification System codes [18].

A total of 97,350 registered patients with a diagnosis of atrial fibrillation from 12 months prior to the study were identified from the SIDIAP database, and all those who had an active prescription for oral anticoagulants on 1 January 2018 were included. All authorized anticoagulant treatments with VKAs (acenocoumarol and warfarin) and DOACs (dabigatran, rivaroxaban, apixaban and edoxaban) in Spain in 2016 were included in the study. Drug data based on ATC codes were collected [18].

\subsection{Inclusion and Exclusion Criteria}

We included patients under treatment with oral anticoagulants and followed in PCCs who had been diagnosed with non-valvular atrial fibrillation at least one year before the study date (1 January 2018) and had at least six controls of the international normalized ratio (INR) over the previous 12 months. This restriction was aimed at minimizing INR variability at the start of the treatment and avoiding the effect of temporary withdrawal of VKAs in patients with good INR control. Patients were considered to have been exposed to anticoagulation if they had been prescribed anticoagulants (acenocoumarol, warfarin, dabigatran, rivaroxaban, apixaban or edoxaban) for at least two months before the start of the study. The anticoagulant medication included in the study was the one which had been started the closest to the study date.

We excluded patients with no oral anticoagulant therapy, patients whose treatment was monitored in hospital, those with valvular atrial fibrillation (mitral stenosis or with a mechanical prosthetic valve), pregnant women, and patients whose anticoagulant treatment at the beginning of the study could not be ascertained.

\subsection{Study Variables}

Main variable. Type of oral anticoagulant prescribed: VKAs (acenocoumarol or warfarin) versus DOACs (dabigatran, rivaroxaban, apixaban or edoxaban), based on ATC classification system codes [18].

Secondary variables. Sociodemographic variables related to patients (gender, age) and the socioeconomic deprivation degree of the PCC geographical area. To measure deprivation, we followed the classification used by the Catalan Health Institute, which uses the MEDEA index [8] to rate urban PCCs according to the deprivation level of each PCC area (the census tract corresponding to the PCC area), which is updated when the census is updated, every 10 years (we used the results calculated for 2018, the period of study). The MEDEA instrument classifies urban areas on a scale from MEDEA 1 (low deprivation) to MEDEA 5 (high deprivation). As a composite deprivation index, it assesses 
barriers to accessing employment, education, culture and social development at a level that is considered acceptable to the society or surrounding region, and it is composed of subindicators for employment and education [5]. As the MEDEA was initially designed for urban areas, based on an analysis of five large Spanish cities [8], rural PCCs were not included in the classification. In our study, rural PCCs were grouped into a separate category and defined as centers serving a population of less than 10,000 inhabitants and with a population density of less than 150 inhabitants $/ \mathrm{km}^{2}$ [19].

Other secondary variables included clinical variables: time since diagnosis of atrial fibrillation; health care setting where oral anticoagulants were prescribed (Primary Care or hospital); history of cardiovascular disease; intracranial bleeding; comorbidities; risk factors for bleeding; risk scores based on participants' real-world data $\left(\mathrm{CHA}_{2} \mathrm{DS}_{2}\right.$-VASC for stroke risk and HAS-BLED for bleeding risk); patients attending outside the PCC (home care or institutionalized care); and teaching PCC. Comorbidities were classified according to the ICD-10 [17].

\subsection{Statistical Analysis}

Data cleaning was performed by verifying minimum and maximum values and by analyzing missing data.

The treatment variable was classified as VKA or DOAC. Once the database was cleaned, a descriptive analysis was undertaken. Categorical variables were expressed as absolute and relative frequencies and continuous variables as median (interquartile range, IQR). Included patients were described according to their treatment and other characteristics, and they were compared by using the two proportion Z-test for categorical variables and the non-parametric Mann-Whitney $U$ test for continuous variables.

To test the association between the type of treatment and the rest of the variables, and to study the factors related to the prescription of DOACs, we calculated the adjusted odds ratio (ORadj) using a multivariable logistic regression model. The statistical analysis was performed using Microsoft Office Excel 2013 (Redmond, Washington, USA) and SPSS version 20.0 software (Armonk, New York, NY, USA).

\section{Results}

The included population comprised 60,978 patients with non-valvular atrial fibrillation on anticoagulant therapy: 41,430 (68\%) taking VKAs and 19,548 (32\%) DOACs.

Regarding gender differences in the type of oral anticoagulant prescribed, a higher proportion of women were prescribed DOACs than men (Table 1). Of the patients receiving DOACs, $50.1 \%$ were women.

Table 1. Description of patient population according to class of oral anticoagulants prescribed.

\begin{tabular}{|c|c|c|c|c|c|}
\hline \multirow{2}{*}{ Variables } & \multicolumn{2}{|c|}{ Vitamin K Antagonists } & \multicolumn{2}{|c|}{ Direct Oral Anticoagulants } & \multirow{2}{*}{$p$ Value } \\
\hline & $n$ * & $\%$ & $n$ * & $\%$ & \\
\hline \multicolumn{6}{|c|}{ Primary care center characteristics } \\
\hline \multicolumn{6}{|c|}{ Classification by rurality and socioeconomic deprivation (urban settings) } \\
\hline MEDEA 1 & 5296 & 12.8 & 3630 & 18.6 & $<0.001$ \\
\hline MEDEA 2 & 6142 & 14.8 & 3230 & 16.5 & $<0.001$ \\
\hline MEDEA 3 & 6457 & 15.6 & 3285 & 16.8 & $<0.001$ \\
\hline MEDEA 4 & 6636 & 16.0 & 3224 & 16.5 & 0.14 \\
\hline MEDEA 5 & 5909 & 14.3 & 2747 & 14.1 & 0.49 \\
\hline Rural & 9350 & 22.6 & 2532 & 13.0 & $<0.001$ \\
\hline Missing & 1640 & 4.0 & 900 & 4.6 & $<0.001$ \\
\hline Prescription in Primary Care & 33,263 & 80.3 & 9009 & 46.1 & $<0.001$ \\
\hline \multicolumn{6}{|l|}{ Care setting outside PCC } \\
\hline Home care & 4926 & 11.9 & 2906 & 14.9 & $<0.001$ \\
\hline Institutional care & 1646 & 4.0 & 1016 & 5.2 & $<0.001$ \\
\hline
\end{tabular}


Table 1. Cont.

\begin{tabular}{|c|c|c|c|c|c|}
\hline \multirow{2}{*}{ Variables } & \multicolumn{2}{|c|}{ Vitamin K Antagonists } & \multicolumn{2}{|c|}{ Direct Oral Anticoagulants } & \multirow{2}{*}{$p$ Value } \\
\hline & $n *$ & $\%$ & $n$ * & $\%$ & \\
\hline \multicolumn{6}{|l|}{ Teaching center } \\
\hline Yes & 11,305 & 27.3 & 5117 & 26.2 & 0.004 \\
\hline Missing & 176 & 0.4 & 124 & 0.6 & 0.001 \\
\hline \multicolumn{6}{|l|}{ Patient characteristics } \\
\hline Total & 41,430 & 67.9 & 19,548 & 32.1 & $<0.001$ \\
\hline Women & 20,285 & 49.0 & 9800 & 50.1 & 0.007 \\
\hline Men & 21,145 & 51.0 & 9748 & 49.9 & 0.007 \\
\hline \multicolumn{6}{|l|}{ Age group } \\
\hline$<60$ years & 935 & 2.3 & 1031 & 5.3 & $<0.001$ \\
\hline $60-69$ years & 4682 & 11.3 & 2893 & 14.8 & $<0.001$ \\
\hline $70-79$ years & 13,654 & 33.0 & 6061 & 31.0 & $<0.001$ \\
\hline$\geq 80$ years & 22,159 & 53.5 & 9563 & 48.9 & $<0.001$ \\
\hline Age in years (median, IQR) & 80.0 & 11.0 & 79.0 & 14.0 & $<0.001$ \\
\hline $\begin{array}{l}\text { Years since diagnosis of atrial fibrillation } \\
\text { (median, IQR) }\end{array}$ & 4.0 & 6.0 & 3.0 & 5.0 & $<0.001$ \\
\hline \multicolumn{6}{|l|}{ History of cardiovascular disease } \\
\hline Peripheral artery disease & 2704 & 6.5 & 1489 & 7.6 & $<0.001$ \\
\hline Ischemic cardiopathy & 7514 & 18.1 & 4108 & 21.0 & $<0.001$ \\
\hline Aortic atheromatosis & 400 & 1.0 & 234 & 1.2 & 0.009 \\
\hline \multicolumn{6}{|l|}{ Cerebrovascular event } \\
\hline Ischemic stroke & 6436 & 15.5 & 4693 & 24.0 & $<0.001$ \\
\hline Unspecified cardiovascular accident & 559 & 1.3 & 392 & 2.0 & $<0.001$ \\
\hline Intracranial bleeding & 364 & 0.9 & 462 & 2.4 & $<0.001$ \\
\hline \multicolumn{6}{|l|}{ Comorbidities } \\
\hline Diabetes mellitus & 13,587 & 32.8 & 6474 & 33.1 & 0.43 \\
\hline Hypertension & 33,360 & 80.5 & 15187 & 77.7 & $<0.001$ \\
\hline Heart failure & 10,846 & 26.2 & 5253 & 26.9 & 0.070 \\
\hline Renal insufficiency & 12,340 & 29.8 & 5281 & 27.0 & $<0.001$ \\
\hline \multicolumn{6}{|l|}{ Bleeding risk factors } \\
\hline Alcohol consumption & 1727 & 4.2 & 843 & 4.3 & 0.41 \\
\hline Brain aneurism & 28 & 0.1 & 35 & 0.2 & $<0.001$ \\
\hline Portal hypertension & 80 & 0.2 & 24 & 0.1 & 0.050 \\
\hline Hepatic insufficiency & 263 & 0.6 & 118 & 0.6 & 0.65 \\
\hline Hereditary hemorrhagic telangiectasia & 2 & 0.0 & 2 & 0.0 & 0.44 \\
\hline Aneurism and aortic dissection & 614 & 1.5 & 322 & 1.6 & 0.12 \\
\hline Intestinal angiodysplasia & 92 & 0.2 & 85 & 0.4 & $<0.001$ \\
\hline Gastrointestinal bleeding & 3286 & 7.9 & 1852 & 9.5 & $<0.001$ \\
\hline $\begin{array}{c}\text { Bleeding other than gastrointestinal or } \\
\text { intracranial }\end{array}$ & 569 & 1.4 & 269 & 1.4 & 0.98 \\
\hline \multicolumn{6}{|l|}{ Stroke risk $\left(\mathrm{CHA}_{2} \mathrm{DS}_{2}-\mathrm{VASC}\right)$} \\
\hline 0 & 404 & 1.0 & 499 & 2.6 & $<0.001$ \\
\hline 1 & 2107 & 5.1 & 1613 & 8.3 & $<0.001$ \\
\hline 2 & 7251 & 17.5 & 3472 & 17.8 & 0.43 \\
\hline 3 & 14,681 & 35.4 & 5820 & 29.8 & $<0.001$ \\
\hline$\geq 4$ & 16,987 & 41.0 & 8144 & 41.7 & 0.12 \\
\hline \multicolumn{6}{|l|}{ Bleeding risk (HAS-BLED) } \\
\hline 0 & 953 & 2.3 & 1063 & 5.4 & $<0.001$ \\
\hline 1 & 14,563 & 35.2 & 7582 & 38.8 & $<0.001$ \\
\hline 2 & 15,112 & 36.5 & 6528 & 33.4 & $<0.001$ \\
\hline 3 & 7783 & 18.8 & 3164 & 16.2 & $<0.001$ \\
\hline$\geq 4$ & 3019 & 7.3 & 1211 & 6.2 & $<0.001$ \\
\hline
\end{tabular}

* Unless otherwise noted. IQR: interquartile range; PCC: Primary Care center.

There were also differences according to the level of socioeconomic deprivation; patients whose PCC area was classified as the least deprived (MEDEA 1) were more likely to be prescribed DOACs $(12.8 \%$ VKA versus $18.6 \%$ DOAC; $p<0.001)$. The smallest 
proportion of patients receiving DOACs were those who attended rural PCCs $(22.6 \%$ VKA versus $13.0 \%$ DOAC; $p<0.001$ ). Figure 1 presents the proportional distribution of VKA and DOAC prescriptions by PCC category (MEDEA index 1 to 5 , rural PCCs). In the centers classified as MEDEA 1, the difference in the prescription between VKAs and DOACs is smaller (59.3\% VKA versus 40.7\% DOAC) than in rural PCCs (78.7\% VKA versus $21.3 \%$ DOAC).

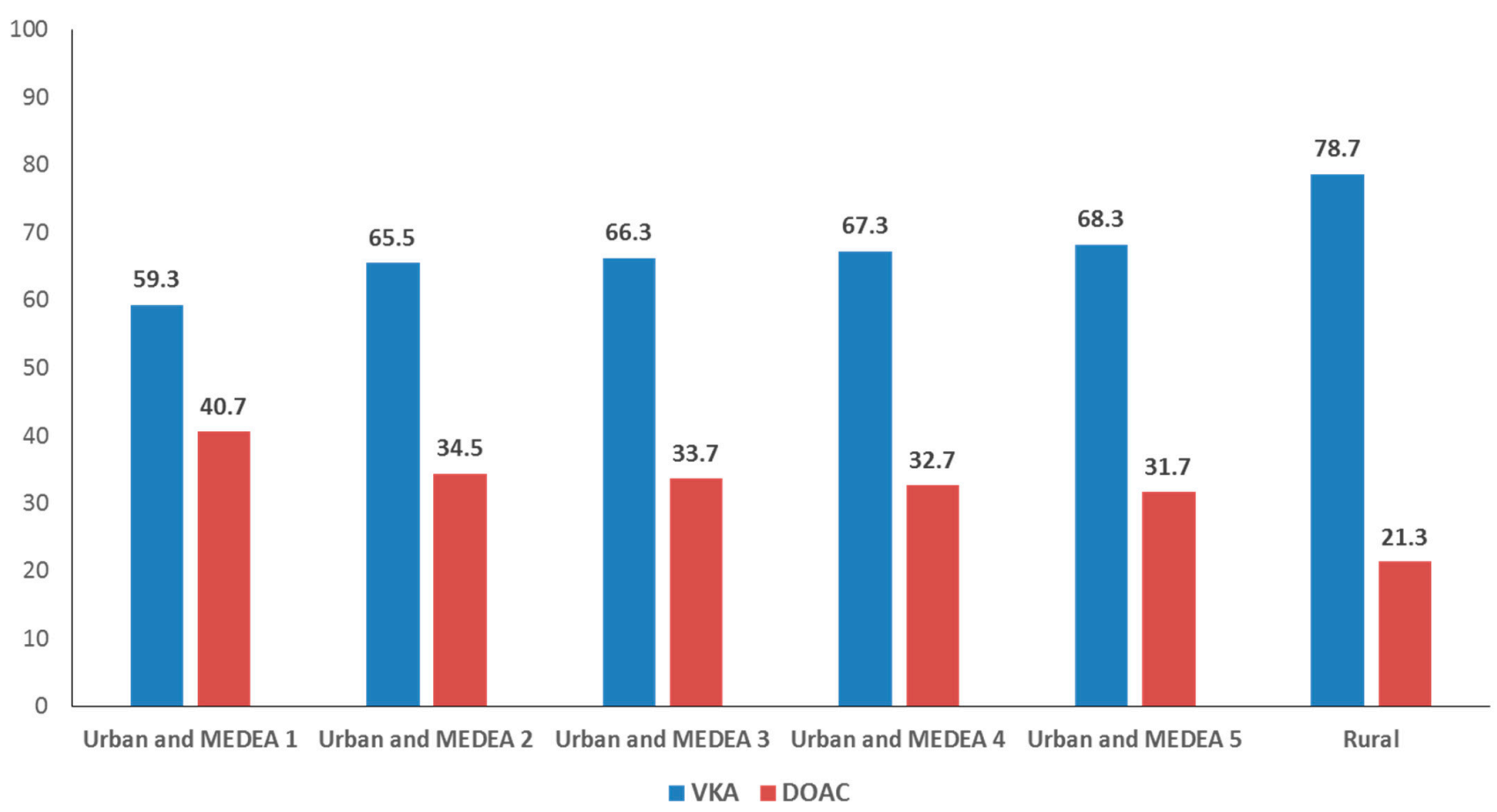

Figure 1. Proportional distribution of prescriptions for vitamin $\mathrm{K}$ antagonists (VKA) versus direct oral coagulants (DOAC) according to the deprivation index of urban Primary Care centers (high MEDEA score = more deprivation) or rurality.

Patients with a history of cardiovascular diseases, cerebrovascular diseases and gastrointestinal bleeding were prescribed DOACs more frequently than VKAs. On the other hand, DOAC prescriptions were more frequent in people with a score of less than 2 on the $\mathrm{CHA}_{2} \mathrm{DS}_{2}$-VASC tool for assessing risk of stroke and in patients who attended outside the PCC premises (home care and institutional care) (Table 1).

According to the results of the logistic regression, the variables associated with differences in prescription of DOACs versus VKAs are: gender, socioeconomic deprivation and rurality. The logistic regression showed that being a woman was associated with DOAC prescription (Table 2). As the level of socioeconomic deprivation rose, the odds of being prescribed DOACs decreased (taking MEDEA 1 levels as the reference). Thus, the highest level of deprivation, MEDEA 5, showed the lowest odds of DOAC prescription among urban areas (ORadj $0.58 ; p<0.001$ ). However, a rural PCC location was the most important factor associated with lower DOAC prescription rates (ORadj 0.34, $p<0.001$; Table 2).

Advanced age, arterial hypertension, renal insufficiency and longer time since diagnosis of atrial fibrillation were associated with a lower frequency of DOAC prescription (Table 2). In contrast, a history of ischemic cardiopathy, peripheral artery disease, heart failure, gastrointestinal bleeding and cerebrovascular events were associated with higher odds of being prescribed a DOAC. 
Table 2. Association between the prescription of direct anticoagulants versus vitamin $\mathrm{K}$ antagonists according to patientand center-related characteristics. Multivariable logistic regression.

\begin{tabular}{|c|c|c|c|}
\hline & OR $_{\mathrm{adj}}$ & $95 \%$ CI & $p$ \\
\hline \multicolumn{4}{|c|}{ Primary care center characteristics } \\
\hline \multicolumn{4}{|c|}{ Classification by rurality and socioeconomic deprivation (urban settings) } \\
\hline MEDEA 1 & 1 & & \\
\hline MEDEA 2 & 0.69 & $(0.65-0.74)$ & $<0.001$ \\
\hline MEDEA 3 & 0.64 & $(0.60-0.68)$ & $<0.001$ \\
\hline MEDEA 4 & 0.61 & $(0.57-0.65)$ & $<0.001$ \\
\hline MEDEA 5 & 0.58 & $(0.54-0.62)$ & $<0.001$ \\
\hline Rural & 0.34 & $(0.32-0.36)$ & $<0.001$ \\
\hline \multicolumn{4}{|l|}{ Care setting outside PCC } \\
\hline Home care & 1.30 & $(1.22-1.37)$ & $<0.001$ \\
\hline Institutional care & 1.20 & $(1.09-1.32)$ & $<0.001$ \\
\hline \multicolumn{4}{|l|}{ Prescription in Primary Care } \\
\hline No & 1 & & \\
\hline Yes & 0.22 & $(0.21-0.23)$ & $<0.001$ \\
\hline \multicolumn{4}{|l|}{ Teaching center } \\
\hline No & 1 & & \\
\hline Yes & 0.88 & $(0.85-0.93)$ & $<0.001$ \\
\hline \multicolumn{4}{|l|}{ Patient characteristics } \\
\hline \multicolumn{4}{|l|}{ Gender } \\
\hline Men & 1 & & \\
\hline Women & 1.12 & $(1.08-1.16)$ & $<0.001$ \\
\hline \multicolumn{4}{|l|}{ Age group } \\
\hline$<60$ & 1 & & \\
\hline $60-69$ & 0.59 & $(0.52-0.66)$ & $<0.001$ \\
\hline $70-79$ & 0.43 & $(0.38-0.47)$ & $<0.001$ \\
\hline$\geq 80$ & 0.41 & $(0.37-0.45)$ & $<0.001$ \\
\hline Years since diagnosis of atrial fibrillation & 0.98 & $(0.97-0.98)$ & $<0.001$ \\
\hline \multicolumn{4}{|l|}{ History of cardiovascular disease } \\
\hline Peripheral artery disease & 1.14 & $(1.05-1.22)$ & $<0.001$ \\
\hline Ischemic cardiopathy & 1.15 & $(1.09-1.20)$ & $<0.001$ \\
\hline Aortic atheromatosis & 1.11 & $(0.93-1.33)$ & 0.26 \\
\hline \multicolumn{4}{|l|}{ Cerebrovascular event } \\
\hline Ischemic stroke & 1.64 & $(1.56-1.72)$ & $<0.001$ \\
\hline Unspecified cardiovascular accident & 1.23 & $(1.06-1.43)$ & 0.005 \\
\hline Intracranial bleeding & 2.70 & $(2.33-3.13)$ & $<0.001$ \\
\hline \multicolumn{4}{|l|}{ Comorbidities } \\
\hline Diabetes mellitus & 1.01 & $(0.97-1.05)$ & 0.62 \\
\hline Hypertension & 0.88 & $(0.83-0.92)$ & $<0.001$ \\
\hline Heart failure & 1.06 & $(1.02-1.11)$ & 0.004 \\
\hline Renal insufficiency & 0.88 & $(0.85-0.93)$ & $<0.001$ \\
\hline \multicolumn{4}{|l|}{ Bleeding risk factors } \\
\hline Alcohol consumption & 0.92 & $(0.83-1.01)$ & 0.094 \\
\hline Brain aneurism & 1.18 & $(0.65-2.13)$ & 0.59 \\
\hline Portal hypertension & 0.61 & $(0.37-1.02)$ & 0.059 \\
\hline Hepatic insufficiency & 0.88 & $(0.68-1.12)$ & 0.29 \\
\hline Hereditary hemorrhagic telangiectasia & 1.27 & $(0.14-11.11)$ & 0.83 \\
\hline Aneurism and aortic dissection & 1.10 & $(0.94-1.30)$ & 0.21 \\
\hline Intestinal angiodysplasia & 1.79 & $(1.30-2.50)$ & $<0.001$ \\
\hline Gastrointestinal bleeding & 1.22 & $(1.15-1.32)$ & $<0.001$ \\
\hline Bleeding other than gastrointestinal or intracranial & 0.92 & $(0.78-1.09)$ & 0.30 \\
\hline
\end{tabular}

ORadj: Adjusted odds ratio; CI: confidence interval; PCC: Primary Care center.

Patients who attended outside the PCC, whether at home or in an institution, were more likely to be prescribed a DOAC. On the other hand, receiving care in a teaching PCC or receiving the anticoagulant prescription in a PCC was associated with lower DOAC prescription rates. Figure 2 shows the proportional distribution of prescriptions (DOAC versus VKA) according to whether the patient received the prescription in or outside a 
PCC. Within PCCs, $21.3 \%$ of the prescriptions for oral anticoagulants are DOACs, while outside the centers, this figure stands at $56.3 \%$.

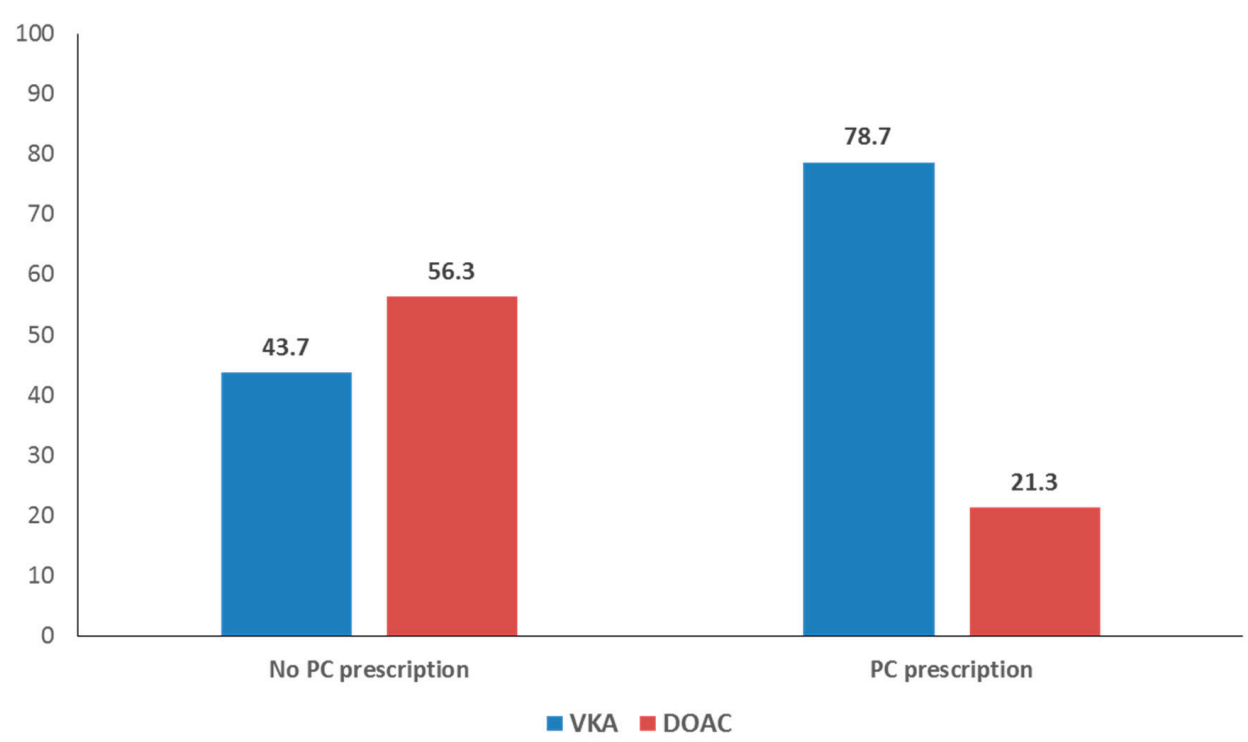

Figure 2. Proportional distribution of prescriptions for vitamin $\mathrm{K}$ antagonists (VKA) versus direct oral coagulants (DOAC) according to whether medication was prescribed inside or outside of a Primary Care center.

\section{Discussion}

This study, analyzing real-world data, identified differences in the prescription of different types of oral anticoagulants (VKA versus DOAC) based on the characteristics of patients and the PCC area. The main factors associated with the type of drug prescribed were gender, socioeconomic deprivation of the urban area and rurality.

Being a woman was associated with more frequent prescriptions for DOACs, after adjusting for the rest of the variables. Lower DOAC prescription was associated with both socioeconomic deprivation and rurality.

The statistical differences detected with regard to gender, deprivation and rurality could reflect inequality in the prescription patterns of oral anticoagulants if these differences are avoidable. If the inequality is unfair, it would represent an example of inequity, an ethical concept that considers inequality on the basis of a values system. The central criterion to define inequality as inequitable is fairness, where inequity is defined as an unfair inequality [20].

Socioeconomic determinants such as education, employment status, income, gender and ethnicity have a clear influence on an individual's health. The lower socioeconomic status a person has, the higher their risk for poor health [20]. Health inequities are systematic differences in the health status of different population groups. These inequities have a high social and economic cost for both individuals and the society as a whole [20]. In Sweden, socioeconomic inequalities in the prescription of oral anticoagulation for preventive treatment after stroke were based on age, income, education and country of birth [11]. In Denmark, patients with atrial fibrillation had a lower chance to being initiated with oral anticoagulation therapy when they had low income, low education and were living alone. Inequality reduced when more detailed new guidelines were published in 2011 [12]. Following clinical guideline recommendations improves adequacy and reduces inequality.

Oral anticoagulants (VKAs and DOACs) are medicines of proven efficacy and effectiveness in preventing thromboembolic events in non-valvular atrial fibrillation. DOACs are considerably more expensive than VKAs, but they are also more practical to use because patients on DOACs do not require close follow-up, as they do on VKAs. In some circumstances, for instance in patients with a history of intracranial bleeding, DOACs 
have also demonstrated more safety [1]. The differences in cost, convenience and even in therapeutic advantages, could be the cause of inequities in prescription patterns that are related to the differences detected in socioeconomic deprivation.

The association between being a woman and being prescribed DOACs shows that women are more likely to receive these drugs than men, even after adjusting for age, medical history, MEDEA index and prescription setting. Other factors not analyzed in this study could also have had an impact, such as polypharmacy (more prevalent in women) or the lower time in therapeutic range observed in women [21]. Gender inequality in the prescription of analgesics and antidepressants is well documented in our country, and the observed differences cannot be fully explained by clinical factors [22]. Specifically, the prescription of analgesics in Spain is more frequent in women than in men, especially in people with a low educational and socioeconomic level [22]. On the other hand, women, especially those with a low socioeconomic status, are more likely to be diagnosed with depression and prescribed antidepressants and other psychotropics. These differences cannot be attributed to a higher frequency of symptoms of depression or visits to Primary Care [7].

Our results also indicate that a younger age is associated with higher prescription of DOACs, even after adjusting for other included variables. Some factors that we did not study may have influenced this result, for example the loss of labor productivity due to follow-up appointments, patient preferences, purchasing power, and co-payments for the medication. However, younger age also tends to indicate less severe pathology, and in turn a lower probability of meeting the current medication appropriateness criteria for DOACs $[23,24]$. Lower age is also associated with a lower $\mathrm{CHA}_{2} \mathrm{DS}_{2}$-VASC score $(<2)$, in which case treatment with oral anticoagulants would not be appropriate [23].

The influence of socioeconomic factors on inequalities in DOAC prescriptions and the relation to its high cost has been studied in different countries. In line with our results, the literature shows that low socioeconomic status is associated with lower use of DOACs in different geographic areas and contexts [3,25]. In Denmark, increasing inequality was observed regarding high-cost drugs, such as DOAC, for the treatment of atrial fibrillation [12]. The way that medications are financed and the type of health system seems to play a relevant role in prescription patterns [3].

The substantial difference in the cost of treatment can hinder the prescription of DOACs in areas affected by greater socioeconomic deprivation, as observed in our study. Rural residence is one of the factors that is most closely associated with lower prescription rates of DOACs. However, the greater convenience associated with following patients treated with DOACs versus VKAs makes the former a more functional treatment for patients who have difficulties in accessing health centers. There is some controversy around whether the higher cost of DOACs compared to VKAs is offset by the lower need for follow-up, making the total healthcare expenditure comparable between the two treatments [26]. Studies being carried out in our context will provide evidence of the cost-effectiveness of both classes of medication [27]. The treatment strategy must consider a holistic, integrated assessment of the patient within the framework of current guidelines.

The MEDEA index used in our study has a limitation in terms of its interpretation, as this index of socioeconomic deprivations is linked to the health center and therefore reflects the index of the census tract corresponding to the basic health area. This means that the patients seen in each PCC may have a different level of deprivation than the area in which they live; although, in general, evidence shows that in population terms, the socioeconomic situation of the census tract is related to mortality in the resident population [19]. Furthermore, potential physician conflicts of interest with pharmaceutical companies cannot always be discarded, which could influence prescription decisions. In other cases, physicians could consider the patient affluent and could prescribe DOAC, which although they are more expensive are more comfortable.

This study opens the door to new studies that can help establish the socioeconomic determinants of inequalities in DOAC prescriptions and assess whether these are avoidable, 
for the ultimate purpose of achieving fairer and more equitable prescription patterns. The inequality observed in prescriptions of oral anticoagulants should be minimized by following current atrial fibrillation management guidelines and addressing modifiable determinants in the pursuit of healthcare equity, better health and social justice.

\section{Conclusions}

This study reveals differences in prescription patterns for oral anticoagulants, specifically in relation to DOACs. Being a woman was associated with higher prescription rates for DOACs, while lower prescription rates were seen in socioeconomically deprived and rural areas. This means that DOACs, co-financed drugs, are prescribed more to women than to men (young), and more to patients with high socioeconomic status than those with low socioeconomic status. These differences could not be explained by the adequacy factors included in the recommendations of the current guidelines for the treatment of atrial fibrillation. Thus, reflecting inadequacy in the treatment. Future studies should identify modifiable factors associated with the inequalities detected. Current atrial fibrillation clinical management guidelines needs to be followed in order to minimize the inequality.

Author Contributions: Conceptualization, M.R.D.L., C.A.M. and J.F.-S.; Data curation, E.C.B. and J.F.-S.; Formal analysis, M.R.D.L., E.C.B. and J.F.-S.; Funding acquisition, M.R.D.L.; Investigation, M.R.D.L., C.A.M., N.C.-Q., Z.H.R. and A.Q.G.; Methodology, C.A.M. and J.F.-S.; Project administration, M.R.D.L.; Supervision, M.R.D.L. and C.A.M.; Validation, M.R.D.L., C.A.M. and J.F.-S.; Visualization, Z.H.R., E.F.D., D.R.C. and J.M.P.V.; Writing—original draft, M.R.D.L., C.A.M., N.C.-Q. and A.Q.G.; Writing-review \& editing, M.R.D.L., N.C.-Q., Z.H.R., E.F.D., D.R.C., E.C.B. and A.Q.G. All authors have read and agreed to the published version of the manuscript.

Funding: Department of Health of the Generalitat de Catalunya, Strategic Plan for Research and Innovation in Health (PERIS), research project number SLT002/16/00146, and Intensification of Specialist Physicians grant SLT008/18/00021 grant.

Institutional Review Board Statement: The study was conducted according to the guidelines of the Declaration of Helsinki, and approved by the Institutional Review Board (or Ethics Committee) of IDIAP Jordi Gol (protocol code P17/091, 15 March 2017).

Informed Consent Statement: Not applicable.

Data Availability Statement: The data that support the findings of this study were obtained from SIDIAP database (Information System for Research in Primary Care). This database is representative of the Catalan population. Restrictions apply to the availability of these data, which were used under license for this study. The authors are not authorized to share the data.

Acknowledgments: The authors thank the following Departments for their contribution: Primary Care Management of the Catalan Institute of Health (ICS), Information Systems of the Primary Care Services, Regional Management and Primary Care Management of the ICS Terres de l'Ebre, Unit of Information Systems of the ICS Regional Management Terres de l'Ebre, Functional Competences Centre of the ECAP of the Information Systems Area and SIDIAP.

Conflicts of Interest: The authors declare no conflict of interest.

\section{References}

1. Hindricks, G.; Potpara, T.; Dagres, N.; Arbelo, E.; Bax, J.J.; Blomström-Lundqvist, C.; Boriani, G.; Castella, M.; Dan, G.-A.; E Dilaveris, P.; et al. 2020 ESC Guidelines for the diagnosis and management of atrial fibrillation developed in collaboration with the European Association for Cardio-Thoracic Surgery (EACTS): The Task Force for the diagnosis and management of atrial fibrillation of the European Society of Cardiology (ESC) Developed with the special contribution of the European Heart Rhythm Association (EHRA) of the ESC. Eur. Heart J. 2020, 42, 373-498. [CrossRef]

2. January, C.T.; Wann, L.S.; Calkins, H.; Chen, L.Y.; Cigarroa, J.E.; Cleveland, J.C., Jr.; Ellinor, P.T.; Ezekowitz, M.D.; Field, M.E.; Furie, K.L.; et al. 2019 AHA/ACC/HRS Focused Update of the 2014 AHA/ACC/HRS Guideline for the Management of Patients with Atrial Fibrillation: A Report of the American College of Cardiology/American Heart Association Task Force on Clinical Practice Guidelines and the Heart Rhythm Society in Collaboration with the Society of Thoracic Surgeons. Circulation 2019, 140, e125-e151. [CrossRef] 
3. Sholzberg, M.; Gomes, T.; Juurlink, D.N.; Yao, Z.; Mamdani, M.M.; Laupacis, A. The Influence of Socioeconomic Status on Selection of Anticoagulation for Atrial Fibrillation. PLoS ONE 2016, 11, e0149142. [CrossRef] [PubMed]

4. Townsend, P.; Corrigan, P.; Kowarzik, U. Poverty and Labour in London: Interim Report of a Centenary Survey; Low Pay Unit: London, UK, 1987.

5. Borrell, C.; Marí-Dell'Olmo, M.; Serral, G.; Martínez-Beneito, M.; Gotsens, M. Inequalities in mortality in small areas of eleven Spanish cities (the multicenter MEDEA project). Health Place 2010, 16, 703-711. [CrossRef] [PubMed]

6. Nathan, A.S.; Geng, Z.; Dayoub, E.J.; Khatana, S.A.M.; Eberly, L.A.; Kobayashi, T.; Pugliese, S.C.; Adusumalli, S.; Giri, J.; Groeneveld, P.W. Racial, Ethnic, and Socioeconomic Inequities in the Prescription of Direct Oral Anticoagulants in Patients with Venous Thromboembolism in the United States. Circ. Cardiovasc. Qual. Outcomes 2019, 12, e005600. [CrossRef] [PubMed]

7. Cabezas-Rodríguez, A.; Bacigalupe, A.; Martín, U. Diagnosis and Treatment of Depression in Spain: Are There Gender Inequalities? Int. J. Environ. Res. Public Health 2020, 17, 9232. [CrossRef] [PubMed]

8. Domínguez-Berjón, M.F.; Borrell, C.; Cano-Serral, G.; Esnaola, S.; Nolasco, A.; Pasarín, M.I.; Ramis, R.; Saurina, C.; Escolar-Pujolar, A. Construcción de un índice de privación a partir de datos censales en grandes ciudades españolas (Proyecto MEDEA). Gac. Sanit. 2008, 22, 179-187. [CrossRef] [PubMed]

9. Mooney, J.; Yau, R.; Moiz, H.; Kidy, F.; Evans, A.; Hillman, S.; Todkill, D.; Shantikumar, S. Associations between socioeconomic deprivation and pharmaceutical prescribing in primary care in England. Postgrad. Med. J. 2020. [CrossRef]

10. Hyun, K.K.; Brieger, D.; Woodward, M.; Richtering, S.; Redfern, J. The effect of socioeconomic disadvantage on prescription of guideline-recommended medications for patients with acute coronary syndrome: Systematic review and meta-analysis. Int. J. Equity Health 2017, 16, 1-10. [CrossRef]

11. Lunde, E.D.; Joensen, A.M.; Fonager, K.; Lundbye-Christensen, S.; Johnsen, S.P.; Larsen, M.L.; Lip, G.Y.; Riahi, S. Socioeconomic inequality in oral anticoagulation therapy initiation in patients with atrial fibrillation with high risk of stroke: A register-based observational study. BMJ Open 2021, 11, e048839. [CrossRef]

12. Sjölander, M.; Eriksson, M.; Asplund, K.; Norrving, B.; Glader, E.-L. Socioeconomic Inequalities in the Prescription of Oral Anticoagulants in Stroke Patients with Atrial Fibrillation. Stroke 2015, 46, 2220-2225. [CrossRef]

13. Essien, U.R.; Magnani, J.W.; Chen, N.; Gellad, W.F.; Fine, M.J.; Hernandez, I. Race/Ethnicity and Sex-Related Differences in Direct Oral Anticoagulant Initiation in Newly Diagnosed Atrial Fibrillation: A Retrospective Study of Medicare Data. J. Natl. Med. Assoc. 2020, 112, 103-108. [CrossRef]

14. Morgan, R.; Klein, S.L. The intersection of sex and gender in the treatment of influenza. Curr. Opin. Virol. 2019, 35, 35-41. [CrossRef]

15. Li, Y.-M.; Jiang, C.; He, L.; Li, X.-X.; Hou, X.-X.; Chang, S.-S.; Lip, G.Y.; Du, X.; Dong, J.-Z.; Ma, C.-S. Sex Differences in Presentation, Quality of Life, and Treatment in Chinese Atrial Fibrillation Patients: Insights from the China Atrial Fibrillation Registry Study. Med. Sci. Monit. 2019, 25, 8011-8018. [CrossRef]

16. Thompson, L.E.; Maddox, T.M.; Lei, L.; Grunwald, G.K.; Bradley, S.M.; Peterson, P.N.; Masoudi, F.A.; Turchin, A.; Song, Y.; Doros, G.; et al. Sex Differences in the Use of Oral Anticoagulants for Atrial Fibrillation: A Report from the National Cardiovascular Data Registry (NCDR (R) PINNACLE Registry. J. Am. Heart Assoc. 2017, 6, e005801. [CrossRef]

17. WHO (World Health Organization). Classification of Diseases (ICD). Available online: https:/ /www.who.int/classifications / classification-of-diseases (accessed on 26 November 2020).

18. World Health Organization. WHOCC-ATC/DDD Index. Available online: https://www.whocc.no/atc_ddd_index/ (accessed on 28 November 2020).

19. Caro-Mendivelso, J.; Elorza-Ricart, J.M.; Hermosilla, E.; Méndez-Boo, L.; García-Gil, M.; Prieto-Alhambra, D. Associations between socioeconomic index and mortality in rural and urban small geographic areas of Catalonia, Spain: Ecological study. J. Epidemiol. Res. 2015, 2, 80. [CrossRef]

20. OMS Health Inequities and Their Causes. Available online: https://www.who.int/news-room/facts-in-pictures / detail/healthinequities-and-their-causes (accessed on 26 November 2020).

21. Llorca, M.D.; Martín, C.A.; Carrasco-Querol, N.; Rojas, Z.H.; Drago, E.F.; Cumplido, D.R.; Blanco, E.C.; Gonçalves, A.; FernándezSáez, J. Anticoagulation Control with Acenocoumarol or Warfarin in Non-Valvular Atrial Fibrillation in Primary Care (Fantas-TIC Study). Int. J. Environ. Res. Public Health 2021, 18, 5700. [CrossRef] [PubMed]

22. Chilet-Rosell, E.; Ruiz-Cantero, M.T.; Sáez, J.F.; Álvarez-Dardet, C. Inequality in analgesic prescription in Spain. A gender development issue. Gac. Sanit. 2013, 27, 135-142. [CrossRef] [PubMed]

23. Dalmau Llorca, M.R.; Aguilar Martín, C.; Carrasco-Querol, N.; Hernández Rojas, Z.; Forcadell Drago, E.; Rodríguez Cumplido, D.; Pepió Vilaubí, J.M.; Castro Blanco, E.; Gonçalves, A.Q.; Fernández-Sáez, J. Oral Anticoagulant Adequacy in Non-Valvular Atrial Fibrillation in Primary Care: A Cross-Sectional Study Using Real-World Data (Fantas-TIC Study). Int. J. Environ. Res. Public Health 2021, 18, 2244. [CrossRef] [PubMed]

24. Ministerio de Sanidad, Servicios Sociales E Igualdad. Criterios y Recomendaciones Generales Para el Uso de los Anticoagulantes Orales Directos (ACOD) en la Prevención del Ictus y la Embolia sistéMica en Pacientes con Fibrilación Auricular no Valvular; UT-ACOD/V5/21112016; Informe de Posicionamento Terapéutico, Agencia Española de Medicamentos y Productos Sanitarios, Madrid, Spain; 2016. Available online: https://www.aemps.gob.es/medicamentosUsoHumano/informesPublicos/docs/ criterios-anticoagulantes-orales.pdf (accessed on 26 November 2020). 
25. Gurusamy, V.K.; Brobert, G.; Vora, P.; Friberg, L. Sociodemographic factors and choice of oral anticoagulant in patients with non-valvular atrial fibrillation in Sweden: A population-based cross-sectional study using data from national registers. BMC Cardiovasc. Disord. 2019, 19, 43. [CrossRef]

26. Jain, R.; Fu, A.-C.; Lim, J.; Wang, C.; Elder, J.; Sander, S.D.; Tan, H. Health Care Resource Utilization and Costs Among Newly Diagnosed and Oral Anticoagulant-Naive Nonvalvular Atrial Fibrillation Patients Treated with Dabigatran or Warfarin in the United States. J. Manag. Care Spéc. Pharm. 2018, 24, 73-82. [CrossRef] [PubMed]

27. Rojas, Z.H.; Llorca, M.R.D.; Martín, C.A.; Gonçalves, A.Q.; Casajuana, M.; Fernández-Sáez, J.; Cumplido, D.R.; Drago, E.F.; Querol, N.C.; Vilaubí, J.M.P.; et al. Cost-effectiveness of direct oral anticoagulants versus vitamin K antagonist in atrial fibrillation. Medicine 2020, 99, e22054. [CrossRef] [PubMed] 